14.P1

\title{
Transplantation of Long-Term Cultured Sympathetic Neurons into the Brains of Parkinsonian Rats
}

\author{
Naoyuki Nakao, Toru Itakura, Yuji Uematsu, Yoshitsgu Ooiwa, and Norihiko Komai \\ Department of Neurological Surgery, Wakayama Medical College, \\ 7-27, Wakayama City, Japan
}

\section{INTRODUCTION}

Functional recovery has been achieved in animal models of Parkinson's disease by transplantation of the sympathetic ganglia, encouraging us to apply the graft therapy to patients with Parkinson's disease $/ 1 /$. In this situation, it is extremely important to maintain donor tissue in culture prior to grafting because in vitro culturing methods give an opportunity to manipulate donor tissue, thereby optimizing conditions for graft survival and function. The present study was designed to evaluate the potential of sympathetic ganglia after being cultured in vitro as a donor tissue for transplantation into the brain of parkinsonian rats.

\section{MATERIALS AND METHODS}

The superior cervical ganglion (SCG) obtained from 2-3 day old Sprague-Dawley rats was divided equally into four pieces. The size of each explant was 400 to $800 \mu \mathrm{m}$ diameter. Cultured explants were grown on collagen-coated plastic dishes and fed with $1 \mathrm{ml}$ of serum-free medium (GIT obtained from Nippon Pharmaceutical Co., Ltd., Tokyo) supplemented with $100 \mathrm{ng} / \mathrm{ml}$ nerve growth factor. Cultures were kept in a humidified $5 \% \mathrm{CO}_{2}$ atmosphere at $37^{\circ} \mathrm{C}$.

After 4-6 weeks culture, these explants were gently scraped from the collagen substrates and suspended in Hank's balanced salt solution for transplantation. Four explants were stereotaxically transplanted into the striatum of unilaterally 6-OHDA-lesioned rats according to the following coordinates: $0.2 \mathrm{~mm}$ rostral to bregma,
$2.8 \mathrm{~mm}$ lateral to the midline, and $5.5 \mathrm{~mm}$ ventral to the dura. Fragments of the sciatic nerve were transplanted in the same manner, serving as a sham-operation. Assessment of apomorphine-induced $(0.25 \mathrm{mg} / \mathrm{kg} \quad$ s.c. $)$ rotational behavior was performed every two weeks after grafting for 12 weeks. Cultured SCG-grafted animals were sacrificed 3-4 months after transplantation and were subjected to catecholamine (CA) histofluorescence study.

\section{RESULTS}

Explants of the SCG began to manifest neurites within 1-2 days after explantation, and many neuritic extensions were observed by 2 weeks in vitro. In the histofluorescence study of the SCG cultured in vitro for 4-6 weeks, CA fluorescent cell bodies survived exclusively in the periphery of the explant.

The rats receiving the cultured SCG $(n=6)$ showed a significant decrease in apomorphineinduced rotation as compared to the sham-operated animals at 4 weeks after grafting (MannWhitney $U$ test; $\mathrm{p}<0.05$ ), and the rotational behavior was compensated by $40-50 \%$ of pregrafted value at 12 weeks after grafting (Figure). In the CA fluorescence study of the cultured SCG-grafted rats, fluorescent CA neurons were found to have survived well in the graft.

\section{CONCLUSION}

The present data demonstrate that the SCG neurons which have been maintained in longterm culture can be successfully grafted, and the 


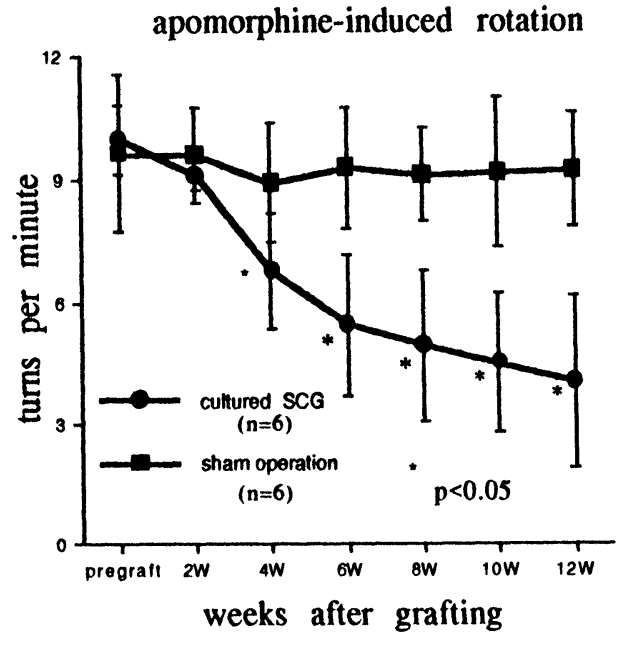

Fig.1 grafts can cause a reduction in apomorphineinduced rotation. Maintaining tissue in culture prior to grafting would make it possible to manipulate donor tissue in vitro to enhance the survival and function of the graft.

\section{REFERENCE}

1. Itakura $\mathrm{T}$ et al. Autotransplantation of the superior cervical ganglion into the brain. J Neurosurg 1988; 68: 555560. 

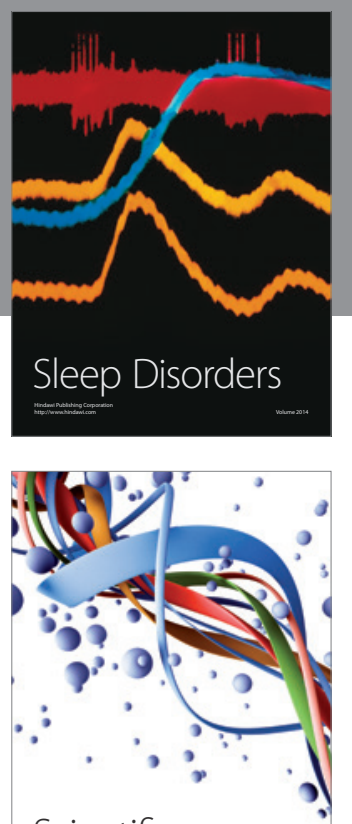

Scientifica
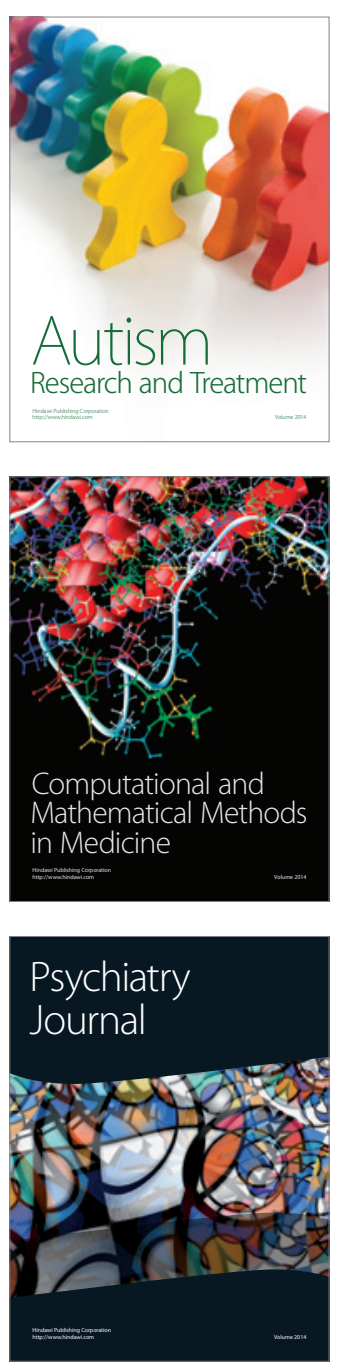
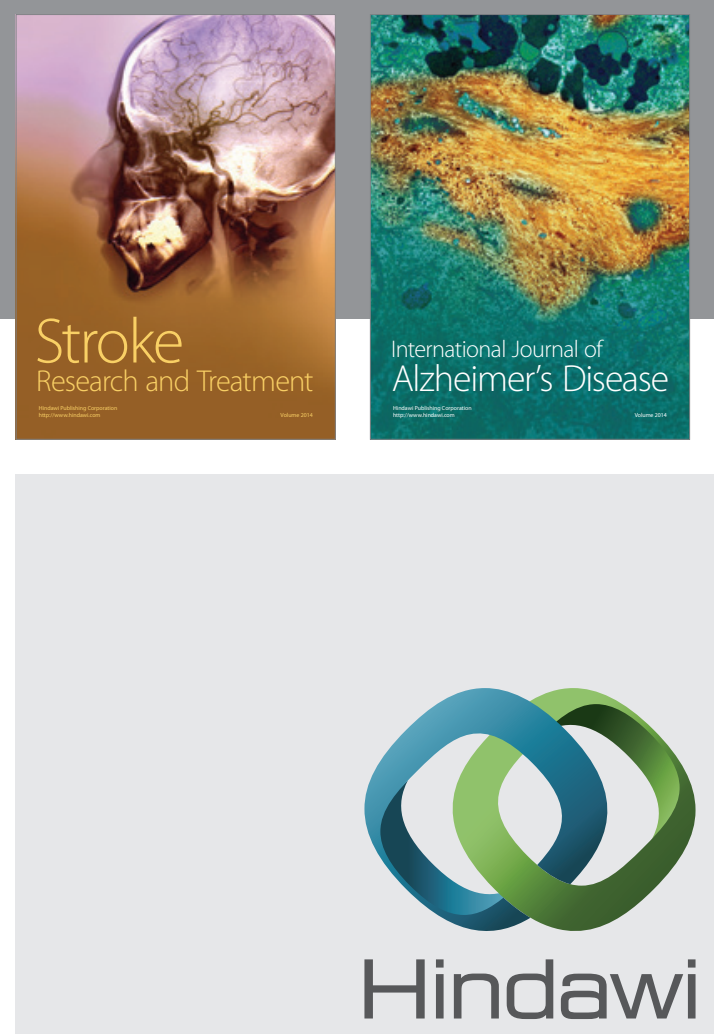

Submit your manuscripts at

http://www.hindawi.com
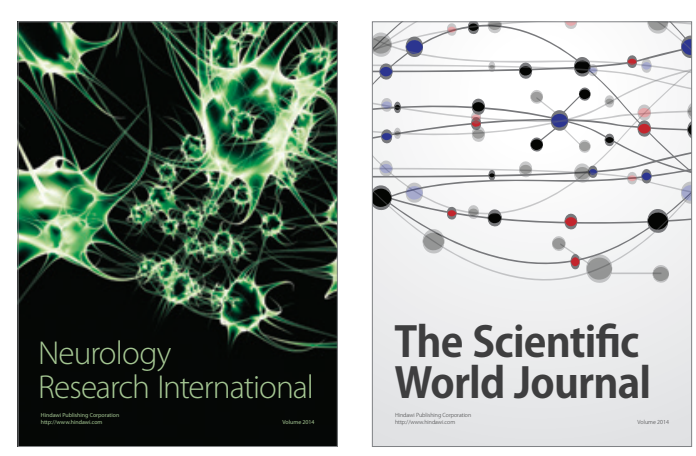

The Scientific World Journal

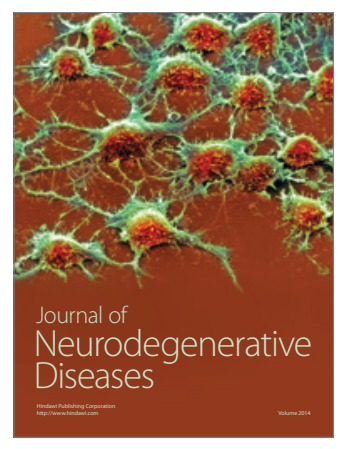

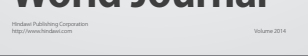

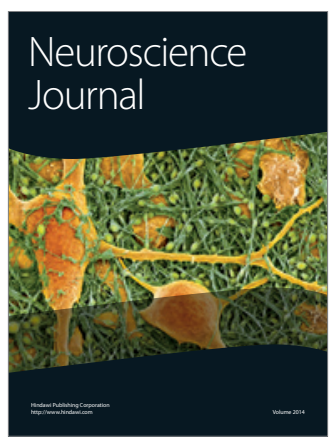

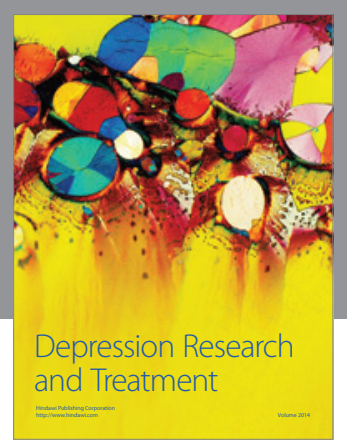
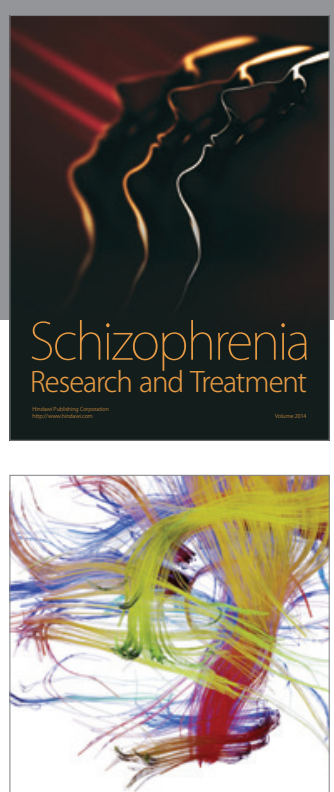

Brain Science

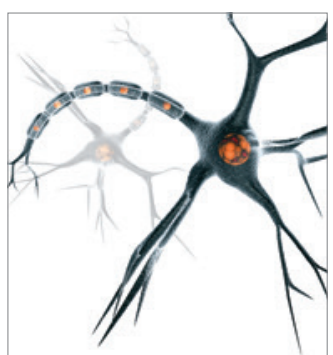

Neural Plasticity
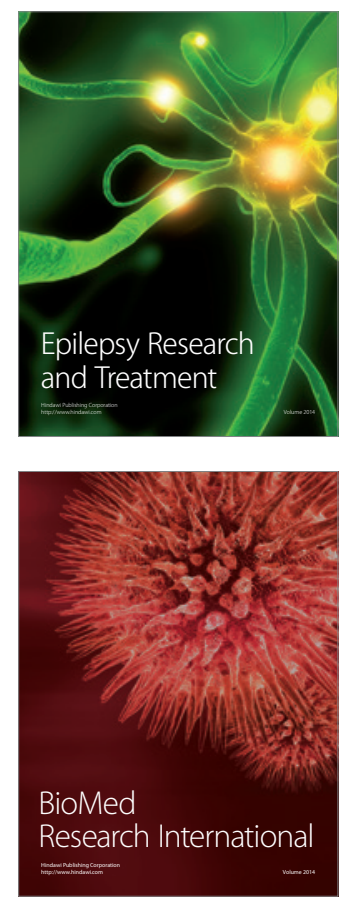

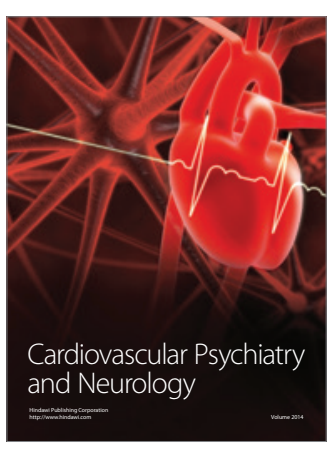

Parkinson's

Disease
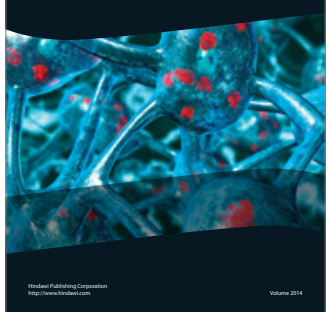